\title{
Tidal motion, ice velocity and melt rate of Petermann Gletscher, Greenland, measured from radar interferometry
}

\author{
ERIC RIGNOT \\ Jet Propulsion Laboratory, California Institute of Technology, Pasadena, California 91109, U.S.A.
}

\begin{abstract}
Over a floating glacier ice tongue or an ice shelf, the glacier motion measured by a single, repeat-pass, radar interferogram is difficult to analyze, because the long-term, steady motion of the ice is intermixed with its cyclic, downward motion induced by tidal forcing. Multiple interferograms and a quadruple-difference technique are necessary to separate the tidal signal from the long-term, steady motion of the ice. An example of application of this technique is given here using ERS1 radar images of Petermann Gletscher, a major outlet glacier of northern Greenland. Tidal displacements are measured with $<5 \mathrm{~mm}$ statistical noise. The long-term ice velocity is measured with a precision of $1 \mathrm{~m} \mathrm{a}^{-1}$. The inferred tidal displacements agree well with model predictions from a fixed elastic beam with an elastic damping factor of $0.47 \pm 0.01 \mathrm{~km}^{-1}$. The hinge line is mapped with a precision of $20-80 \mathrm{~m}$.

Combining the interferometric ice velocities with ice thickness data, the glacier ice discharge is calculated at and below the hinge line. At the hinge line, the ice flux is $12.1 \pm 1 \mathrm{~km}^{3} \mathrm{a}^{-1}$. At the ice front, calf-ice production is only $0.59 \mathrm{~km}^{3} \mathrm{a}^{-1}$, meaning that $95 \%$ of the ice that crosses the grounding line melts before it reaches the calving front. Assuming steady-state conditions, the melt rate of the glacier tongue averages $12 \pm 1 \mathrm{~m} \mathrm{a}^{-1}$, with peak values exceeding $20 \mathrm{~m} \mathrm{a}^{-1}$ near the hinge line. This high melt rate cannot be accommodated by surface ablation alone (only about $2-3 \mathrm{~m} \mathrm{a}^{-1}$ ) and is attributed to pronounced basal melting of the ice tongue. Basal melting, often assumed to be negligible in Greenland, is the dominant process of mass release from the floating section of Petermann Gletscher.
\end{abstract}

\section{INTRODUGTION}

Calving glaciers play an essential role in the dynamics and mass balance of the Greenland ice sheet, and even more so in the case of the Antarctic ice sheet where ice shelves and floating glacier ice tongues develop extensively (Holdsworth, 1977; Drewry and Robin, 1983; Vaughan and Doake, 1996). Of particular interest for studies of the stability of these glaciers is the region at the junction between slower-moving inland ice where no tidal displacements occur and faster-moving ice comprising the ice tongue or ice shelf where tidal forcing introduces a cyclic, vertical motion of the ice surface. The grounding line, where the ice decouples from the glacier bed and becomes afloat, is important to locate precisely, because it provides a reference for monitoring changes in ice thickness or sea level induced by climatic change (Thomas and Bentley, 1978).

Tidal ice-shelf flexure may be measured by tiltmeters (Smith, 1991) or precise global positioning system (GPS) kinematic surveys (Vaughan, 1995). Locating the grounding line is more difficult by traditional standards, and there are no systematic means of mapping its position using a remote-sensing instrument. Goldstein and others (1993) detected the tidal motion of the Rutford Ice Stream using a single ERS-1 interferogram, and deduced the position of the grounding line within
$500 \mathrm{~m}$. Because both the tidal displacements and the ice velocity contribute to the observed range displacements in the ERS interferogram, they had to use an independent estimate of the ice velocity to locate the zone of flexing of the glacier precisely in the interferogram. Using two interferograms, Hartl and others (1994) demonstrated that the tidal motion of an ice shelf could be isolated from the rest of the signal. The basic premise for the method is to assume that over the time-scale considered for repeat-pass interferometric applications (several days) the ice motion other than that due to tidal forcing is steady and continuous and therefore may be eliminated by differencing of two successive radar interferograms.

In this work, the same premise is used, but the additional effect of surface topography is incorporated in the analysis. In addition, I propose a method to subsequently eliminate the tidal signal from individual radar interferograms, so that it is also possible to estimate the long-term steady motion of the ice. I apply this quadruple-difference interferometry technique to ERS radar images of Petermann Gletscher, a major outlet glacier of northern Greenland, which has an extensive floating ice tongue confined within a fjord. Numerous rock outcrops are present at the margins of the glacier to provide a reliable, fixed reference for estimating the interferometric baselines, georeferencing the data and 
studying glacial motion. Data coverage of that part of Greenland by the ERS-1 radar system has been excellent, and S. Ekholm and R. Forsberg of KMS (Kort and Matrikelstyrelsen) have produced a precise topographic map of the area. The objectives of this study were to utilize ERS-1 radar interferometry data to measure the tidal displacements of the ice tongue, map the grounding line of the glacier and study its ice discharge at and below the grounding line. A companion study by Joughin and others (1995a) examined the ice velocity of Petermann Gletscher higher up in its accumulation area.

\section{STUDY AREA}

Petermann Gletscher is located $60^{\circ} \mathrm{W}$ and $81^{\circ} \mathrm{N}$, on the northwestern flank of the Greenland ice sheet (Higgins, 1991, figs 1 and 2). Petermann Gletscher was first documented and examined during the American Polaris expedition under C. F. Hall in 1871 (Kollmeyer, 1980). It is one of the few Arctic glaciers which develops an extensive floating ice tongue. Its terminus, only 3-4 m a.s.l., occasionally disintegrates to yield tabular icebergs $30-50 \mathrm{~m}$ thick, up to $10 \mathrm{~km} \times 12 \mathrm{~km}$ in area Dunbar, 1978; Kollmeyer, 1980). Petermann Gletscher has the highest measured velocity of a northern Greenland glacier, about $0.95 \mathrm{~km} \mathrm{a}^{-1}$ at the ice front (Higgins, 1991).

This study utilizes three consecutive passes of the ERS-1 satellite acquired on 25 and 28 February and 2 March 1992, during orbits 3205, 3248 and 3291. Each radar scene is a $100 \mathrm{~km} \times 100 \mathrm{~km}$ frame, with a $20 \mathrm{~m}$ pixel spacing on the ground after averaging of 5 pixel elements in the azimuth (or along-track) direction. In the radar imagery (Fig. 1), the shear margins of the glacier are pronounced, and extend far southward into the inland ice. Most of the glacier surface within the fjord is radar-dark, indicating a surface poorly reflective of ERS radar signals. The radar-bright region to the south marks the edge of the percolation facies which is radar-bright because of internal reflections in subsurface icy inclusions (Rignot and others, 1993; Rignot, 1995). Five glaciers descend on the east side from Kane Plateau to merge with the main ice stream, the most important one being Porsild Gletscher (Higgins, 1991).

\section{METHODS}

\section{Interferogram generation}

Readers interested in background information on radar interferometry may consult Zebker and Goldstein (1986), Goldstein and others (1988), Gabriel and others (1989) and Zebker and others (1994). The basic principles of radar interferometry will not be repeated here.

Two interferograms were formed using image 2 (orbit 3248 ) as the reference image. The complex amplitude radar images were first co-registered with sub-pixel accuracy, including additional pixel offsets over the fast-moving part of the ice. The registered images were then cross-correlated. The normalized correlation or phase coherence of the cross-products, denoted $\rho$, taking values between 0 (no coherence) and 1 (perfect temporal coherence), is high $(\rho>0.8)$ over most of the scene, yielding high-quality interferometric fringes (Fig. 2). Phase unwrapping was performed using Goldstein and others' (1988) unwrapping algorithm after smoothing of the data using a two-dimensional spectral filter.

Upstream of the grounding line, the interferograms exhibit a complex pattern of closely spaced fringes $\left(360^{\circ}\right.$ variations in phase) with pairs of concentric circles where phase unwrapping is difficult to perform. A similar fringe pattern is seen in radar interferograms of the southwestern flank of the Greenland ice sheet. The pairs of concentric circles are attributed to variations in the vertical component of the ice-motion vector as ice flows past bumps and hollows in surface topography, several meters in height and several kilometers in diameter, created by faster ice-sheet flow over the bedrock topography near the ice margin (Joughin and others, 1995b; Rignot and others, 1995). In those regions of more rapidly varying surface slope, phase coherence is reduced compared to that of the surrounding ice, because the

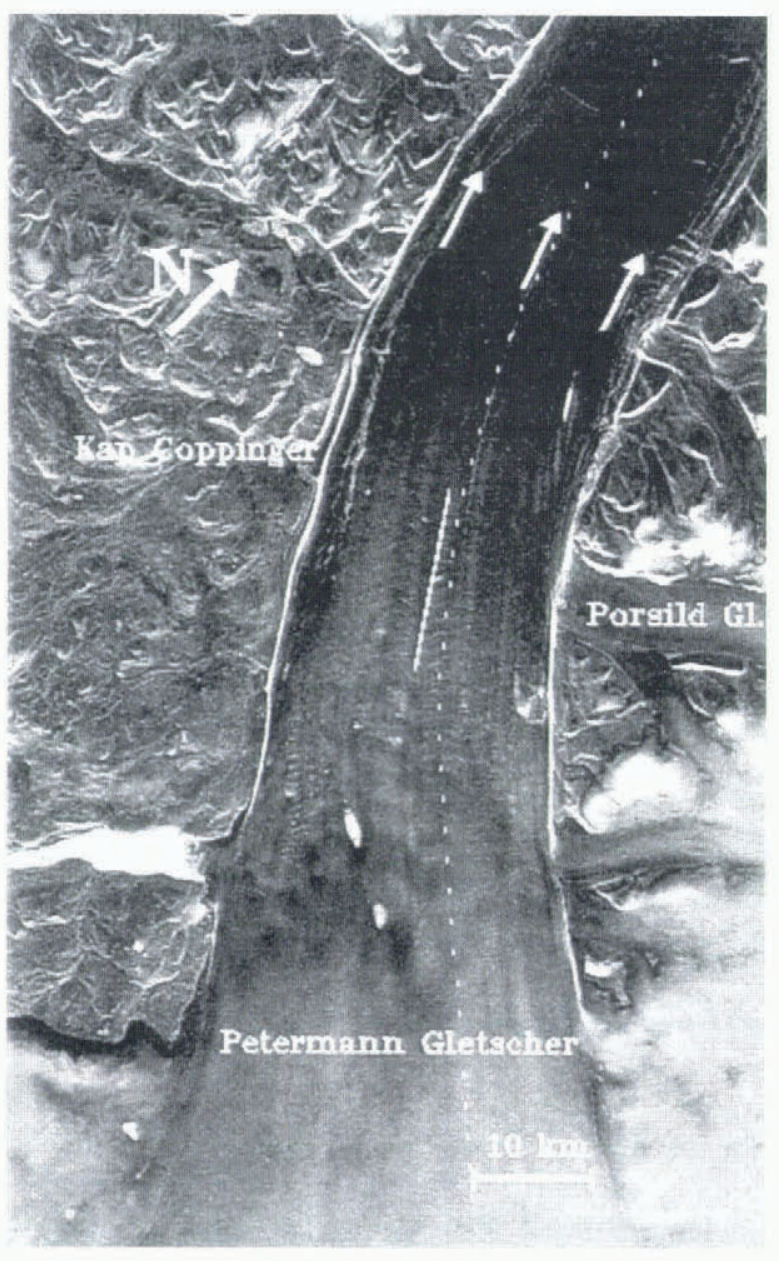

Fig. 1. ERS-1 radar amplitude image of Petermann Gletscher, $60 \mathrm{~km}$ by $100 \mathrm{~km}$ in size, acquired on 25 February 1992. North is upwards, ERS-I is flying from east to west, looking north to its right. The white continuous line locates the tidal profile shown in Figure 6. The dolted white line represents the dynamic centerline of the glacier. The flow direction is indicated schematically by arrows. North is indicated by an arrow. (C) ESA 1992. 


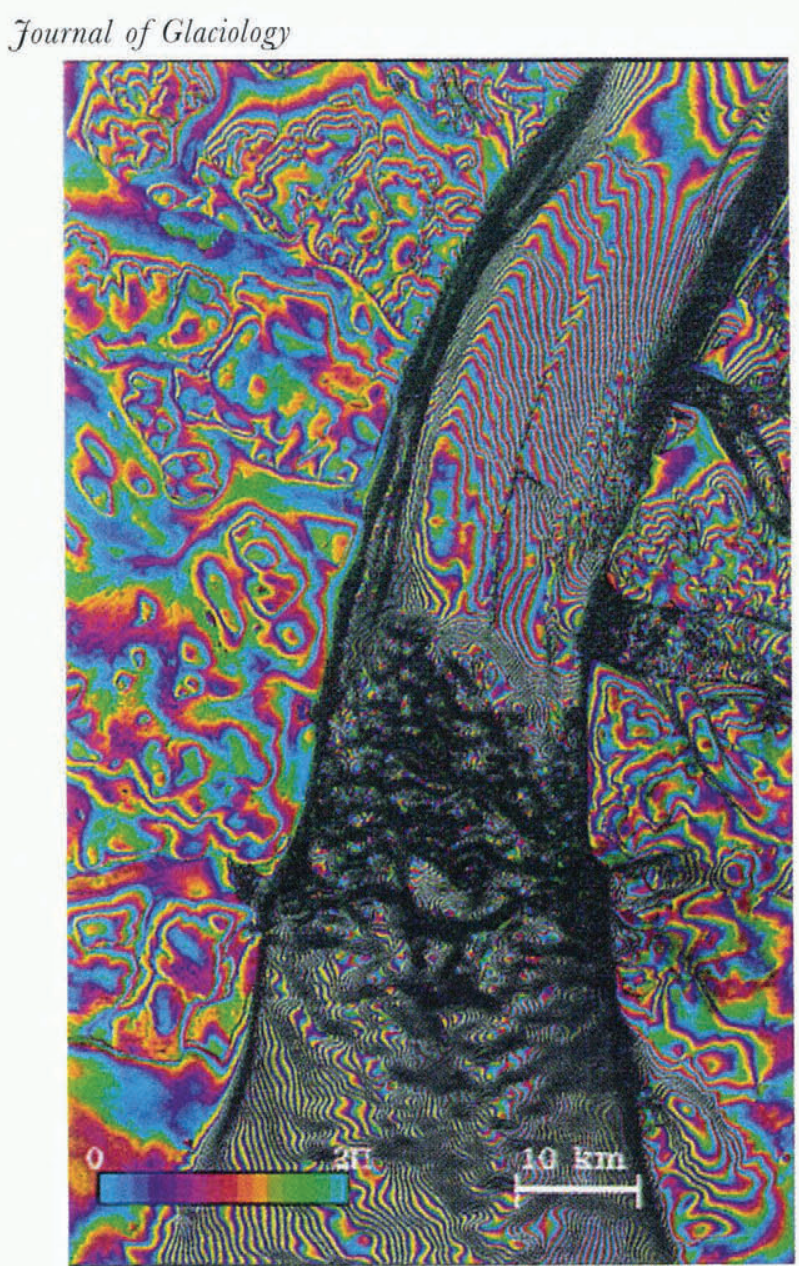

Fig. 2. Flattened interferogram combining orbits 3205 and 3248 , with a color intensity modulated by phase coherence. Dark areas indicate low phase coherence.

illumination angle of the ice blocks changes slightly as they move past the bumps and hollows in surface topography.

The baseline or distance separation between the successive positions of the ERS radar antenna was estimated by least-square fitting using 1400 tie-points selected from a digital elevation model (DEM) of the glacier, $0.005^{\circ}$ in latitude spacing and $0.025^{\circ}$ in longitude spacing, provided by S. Ekholm and R. Forsberg of KMS and referenced to sea level. The KMS DEM data were projected into the radar-imaging geometry, interpolated using a bilinear interpolation, and registered to the radar scene within 1-2 image pixels using one tie-point.

\section{Interferometric products}

I denote $V_{x}, V_{y}, V_{z}$ the components of the steady-motion vector of the ice along the $x, y$ and $z$ axes. The term "steady" here refers to the ice motion over a time-scale much larger than the tidal cycle. The $x$ axis is in the crosstrack direction, pointing north. The $y$ axis is in the alongtrack direction, pointing west. The $z$ axis is the vertical axis. Under tidal influence, the ice tongue undergoes upward and downward motion along the $z$ axis of amplitude $Z$. I use the sign convention that the phase, $\phi$, measured by the radar is equal to $-4 \pi R / \lambda$, where $R$ is the range distance between a point at the surface of the glacier and the center of the synthetic aperture, and $\lambda$ is the radar wavelength $(5.66 \mathrm{~cm}$ for ERS-1 radar). The phase difference, $\phi_{12}=\phi_{2}-\phi_{1}$, measured between antennae 1 (orbit 3205) and 2 (3248), may then be expressed as

$$
\begin{aligned}
\phi_{12}= & \frac{4 \pi}{\lambda}\left[B_{12 \perp} \sin \left(\delta \theta_{z}\right)-B_{12 \|} \cos \left(\delta \theta_{z}\right)+\frac{B_{12}{ }^{2}}{2 R}\right] \\
& +\frac{4 \pi}{\lambda}\left[-V_{x} \sin (i)+V_{z} \cos (i)\right]\left(t_{2}-t_{1}\right) \\
& +\frac{4 \pi}{\lambda}\left(Z_{2}-Z_{1}\right) \cos (i)+\phi_{12}{ }^{\circ}
\end{aligned}
$$

where $B_{12}$ is the baseline or distance separating antennae 1 and 2, $\theta_{z}$ is the illumination angle with the horizontal for a point at elevation $z, \delta \theta_{z}$ is equal to $\theta_{z}-\theta_{0}, \theta_{0}$ is the illumination angle with the horizontal at the center of the scene for a point at a reference elevation $z=0, \alpha_{12}$ is the baseline angle with the horizontal, $B_{12 \perp}=B_{12} \sin$ $\left(\theta_{0}+\alpha_{12}\right)$ is the component of the baseline perpendicular to the direction of the radar illumination, $B_{12 \|}=$ $B_{12} \cos \left(\theta_{0}+\alpha_{12}\right)$ is the component of the baseline parallel to the direction of the radar illumination, $\left(t_{2}-t_{1}\right)$ is the time lag between the two images, $i$ is the local incidence angle of the radar illumination with the vertical, and $\phi_{12}{ }^{\circ}$ is an absolute phase offset.

The first line of Equation (1) depends only on the glacier topography and is scaled by both the baseline and the radar wavelength. The second line is the term of ice motion along the radar line of sight caused by the steady motion of the ice. The component $V_{y}$ is absent from Equation (1) because the $y$ axis is parallel to the flight direction, and surface displacements are not measured in that direction. The third line corresponds to changes in surface elevation along the radar line of sight caused by the downward motion of the ice under tidal forcing. With a second interferogram combining images 2 and 3, I obtain

$$
\begin{aligned}
\phi_{32}= & \frac{4 \pi}{\lambda}\left[B_{32 \perp} \sin \left(\delta \theta_{z}\right)-B_{32 \|} \cos \left(\delta \theta_{z}\right)+\frac{B_{32}^{2}}{2 R}\right] \\
& +\frac{4 \pi}{\lambda}\left[-V_{x} \sin (i)+V_{z} \cos (i)\right]\left(t_{2}-t_{3}\right) \\
& +\frac{4 \pi}{\lambda}\left(Z_{2}-Z_{3}\right) \cos (i)+\phi_{32}^{\circ}
\end{aligned}
$$

with a different baseline separation, $B_{32}$, angle, $\alpha_{32}$, and relative tidal displacement, $Z_{2}-Z_{3}$; but with the same ice motion vector, $V_{x}$ and $V_{z}$.

If radar scenes 1, 2 and 3 are acquired in sequence and exactly $3 \mathrm{~d}$ apart, adding Equations (1) and (2) eliminates the term of steady ice motion

$$
\begin{aligned}
\phi_{12}+\phi_{32}= & \frac{4 \pi}{\lambda}\left[\left(B_{12 \perp}+B_{32 \perp}\right) \sin \left(\delta \theta_{z}\right)\right. \\
& -\left(B_{12 \|}+B_{32 \|}\right) \cos \left(\delta \theta_{z}\right)+\frac{B_{12}{ }^{2}+B_{32}{ }^{2}}{2 R} \\
& +\left[\left(2 Z_{2}-Z_{3}-Z_{1}\right) \cos (i)\right]+\phi_{12}{ }^{\circ}+\phi_{32}{ }^{\circ}
\end{aligned}
$$

Using tie-points from the KMS DEM on both rock and ice, at the exclusion of the floating section, I estimate the baseline parameters of Equation (3) and remove the topography term to obtain

$$
\phi_{12, \text { flat }}+\phi_{23, \text { flat }}=\frac{4 \pi}{\lambda}\left(2 Z_{2}-Z_{3}-Z_{1}\right) \cos (i)
$$


which depends only on the tidal displacements. The subscript "flat" designates a phase value for which the effect of the baseline and of surface topography has been removed. The map of the relative tidal displacement, $Z_{2}-0.5\left(Z_{3}-Z_{1}\right)$, between scene 2 and the average of scenes 1 and 3, is shown in Figure 3.

Model predictions from the elastic-beam theory indicate that tidal displacements at a given point along an elastic beam vary linearly with the tidal amplitude. Several experimental studies have shown that the elasticbeam model matches observations of tidal displacements well (Holdsworth, 1969). If we assume that tidal forcing is the same everywhere along the beam as in Holdsworth's (1969) study and that the elastic damping factor of the ice does not change with tidal amplitude (Holdsworth, 1977), a different realization of tidal forcing should exhibit the same pattern of tidal displacement as that given in Equation (4), scaled by a different relative tidal amplitude. Under these circumstances, I rewrite Equation (1) after removal of the topography term as

$$
\begin{aligned}
\phi_{12 \text { flat }}= & \frac{4 \pi}{\lambda}\left[-V_{x} \sin (i)+V_{z} \cos (i)\right]\left(t_{2}-t_{1}\right) \\
& +\gamma_{12}\left[\phi_{12, \text { flat }}+\phi_{23, \text { flat }}\right]+\phi_{12}{ }^{\circ}
\end{aligned}
$$

which yields the ice velocities, $V_{x}$ and $V_{z}$, once $\gamma_{12}$ is

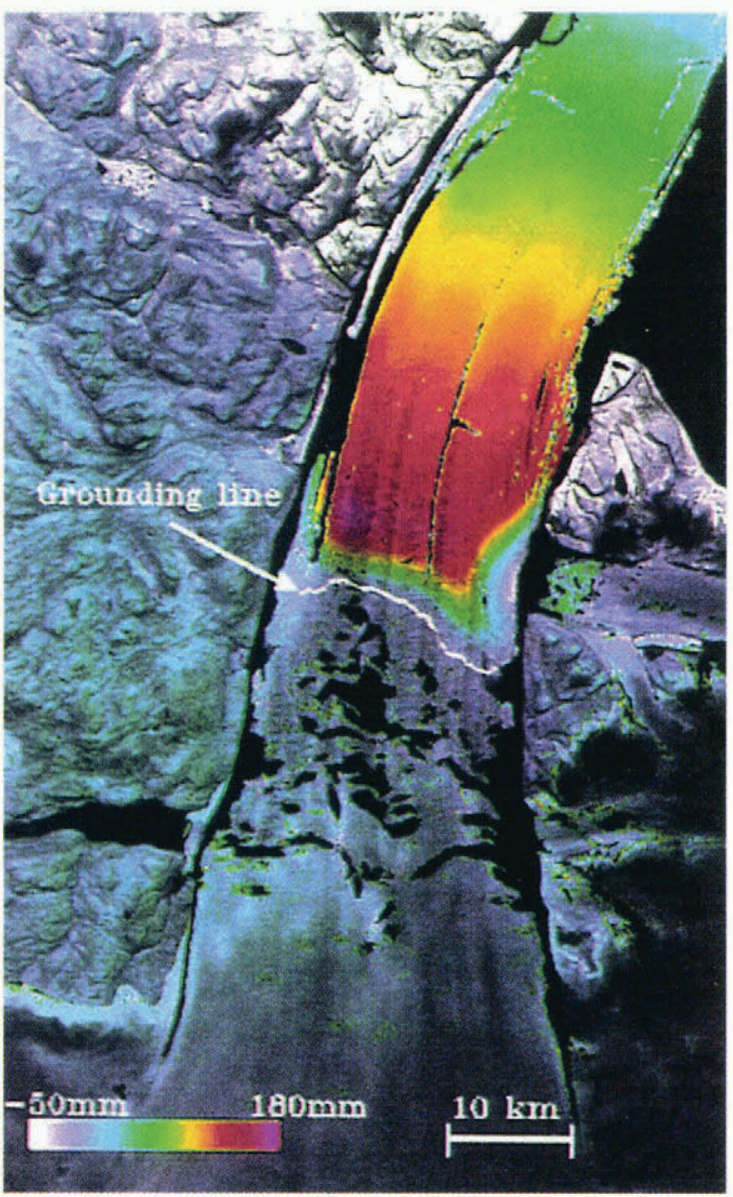

Fig. 3. Tidal displacements (color-coded between -50 and $180 \mathrm{~mm}$ and modulated by the radar brightness for display purposes), and hinge line (continuous white line) of Petermann Gletscher. Dark patches indicate areas with no interferometric data. known. To determine $\gamma_{12}$, either the tidal amplitude or the ice velocity must be known at one location, otherwise there is an infinite number of solutions for $\gamma_{12}$.

Here, I estimated 11 control velocities by tracking a set of crevasses below the grounding line in two ERS-1 radar images separated by 1 year. The rms error in the velocity estimates is $50 \mathrm{~m} \mathrm{a}^{-1}$. The least-square estimate of $\gamma_{12}$ is $1.8 \pm 0.2$.

The $x$ velocity, $V_{x}$, is deduced from Equation (5) assuming $V_{z}=0$. In effect, the vertical motion associated with glacier thinning is negligible compared to the horizontal motion, and ice flows nearly in the horizontal plane since the glacier slope is less than $1 \%$. The $x$ velocity was subsequently transformed into a twodimensional velocity by assuming a flow direction parallel to the dynamic center line of the glacier (dotted line in Figure 1). The dynamic center line was drawn based on intense surface crevassing at the center of the floating part of the glacier and using the line of maximum $x$ velocity on grounded ice. The result is shown in Figure 4.

Once the tidal amplitude is known, it is also possible to estimate the glacier topography, at an enhanced spatial resolution compared to the KMS DEM. A color composite image of the glacier topography is shown in Figure 5. Holes correspond to areas where phase unwrapping failed because of low phase coherence.

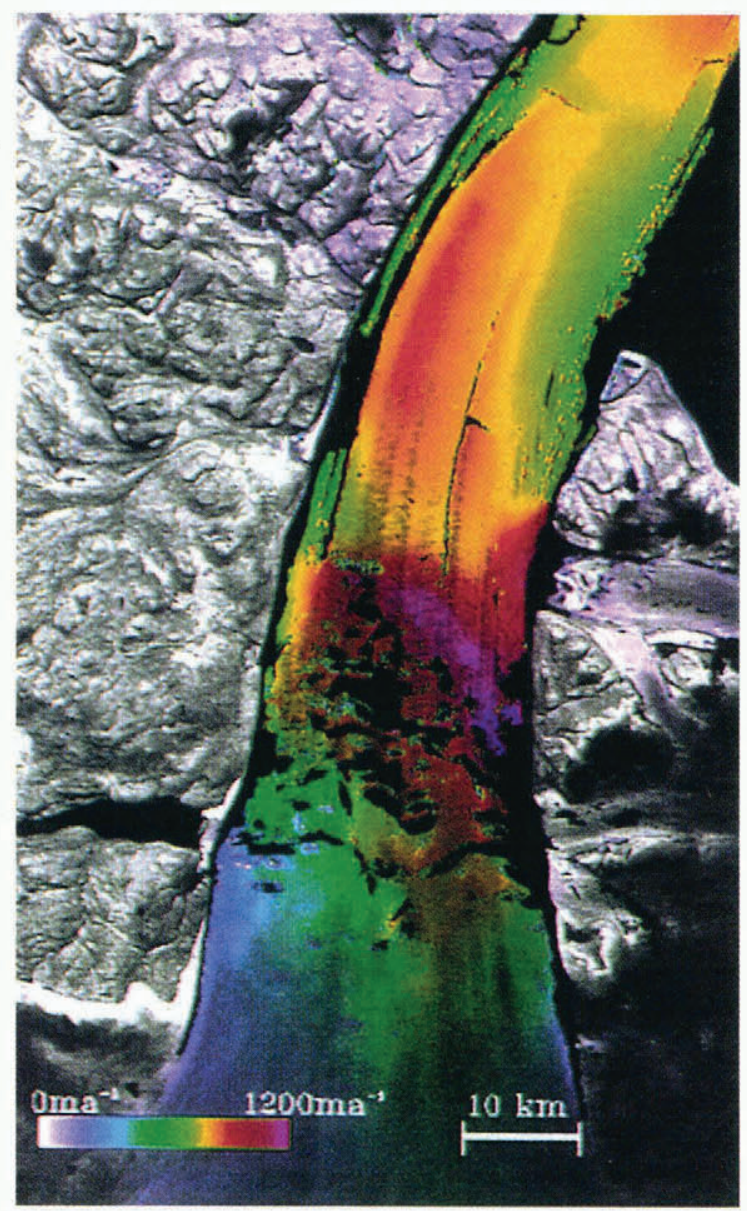

Fig. 4. Ice velocity of Petermann Gletscher, color-coded between 0 and $1200 \mathrm{ma}^{-1}$, and modulated by the radar brightness. Dark patches indicate areas with no interferometric data. 


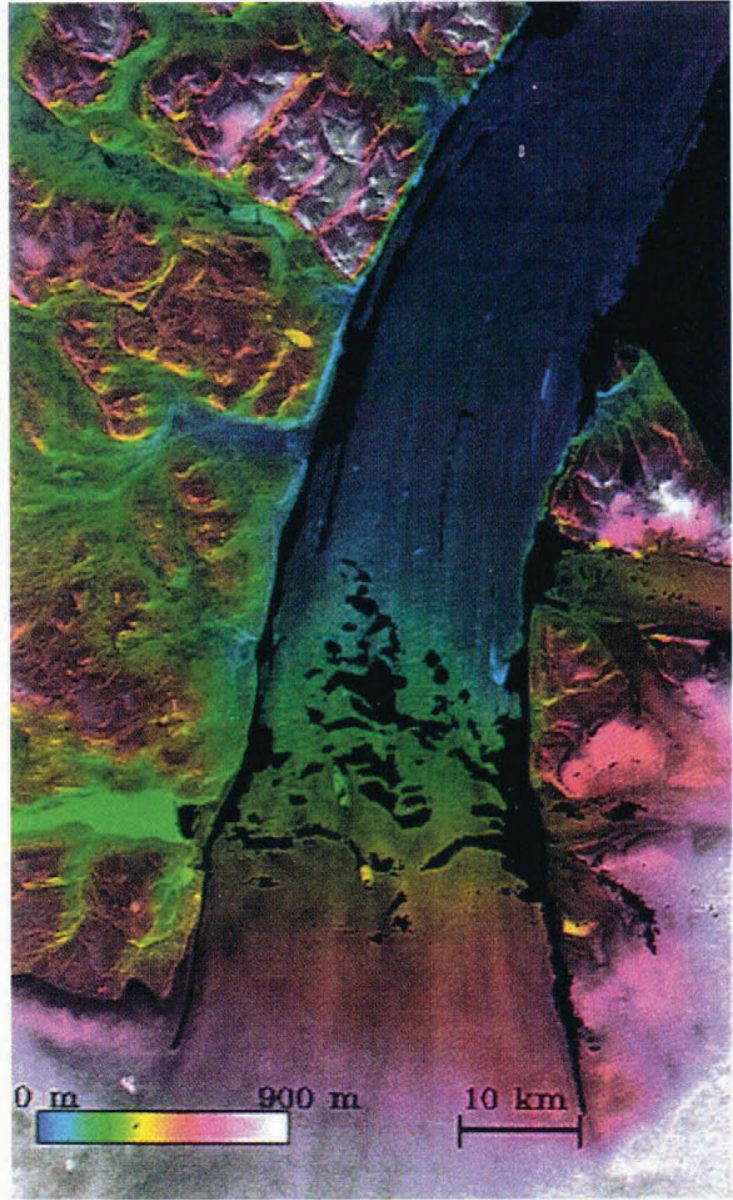

Fig. 5. Surface topography of Petermann Gletscher colorcoded between 0 and $900 \mathrm{~m}$. Dark patches indicate areas with no interferometric data.

\section{Measurement uncertainties}

The rms error of the phase values calculated during the baseline estimation process was 3 rad for pair 3248-3205 (Equation (1)), 0.6 for pair 3248-3291 (Equation (2)) and 5 for the two pairs combined (Equation (3)). These phase errors translate into uncertainties in surface topography of, respectively, 75, 400 and $100 \mathrm{~m}$. The errors are large because the perpendicular baselines are short (respectively 58, 2 and $60 \mathrm{~m}$ ). The velocity errors are conversely small because they do not depend on the baseline separation and are, respectively, equal to 4 and $1 \mathrm{~mm} \mathrm{~d}^{-1}$ for the individual pairs, which means about $1 \mathrm{~m} \mathrm{a}^{-1}$ uncertainty in ice velocity; and $10 \mathrm{~mm}$ for the two pairs combined, which means $5 \mathrm{~mm}$ uncertainty in relative tidal displacement. These errors are, respectively, three orders of magnitude less than the velocity of the glacier $\left(1000 \mathrm{~m} \mathrm{a}^{-1}\right)$ and two orders of magnitude less than the largest relative tidal displacement which can be recorded over a complete cycle $(800 \mathrm{~mm}$; see below).

Errors in tidal displacement are visible in several areas outside of the main ice stream of Petermann Gletscher. For instance, in the center top of the scene, running almost east-west, a $10 \mathrm{~km}$ wide segment shows a relative tidal displacement of -10 to $-50 \mathrm{~mm}$ (colored white in Figure 3) outside of the glacier area. This anomaly coincides with the ice-covered areas of Washington Land and Kane Plateau (see Higgins, 1991, fig. 2). This error is probably not due to baseline uncertainties, since its magnitude does not increase with surface elevation. It is probably due to a combination of atmospheric and ionospheric propagation delays (Goldstein, 1995), and surface effects including for instance a change in snow thickness of the ice caps. To average out these errors, additional interferograms are necessary.

\section{RESULTS}

\section{Tidal displacements}

The pattern of relative tidal displacements (Fig. 3) delineates the part of the glacier that is afloat. Nearly the entire section of the glacier below the grounding line undergoes tidal motion, with a sharp discontinuity between the rock margin and the ice tongue. This observation suggests there is little mechanical coupling between the ice tongue and the rock margin. The tidal displacements increase rapidly from zero to a maximum value about $6 \mathrm{~km}$ downstream, and subsequently decrease slowly toward an asymptotic value.

On the eastern side of the glacier, where Porsild Gletscher merges with the main stream of Petermann Gletscher, the pattern of tidal displacement is more complex. Phase unwrapping failed at the junction between the two glaciers, but Porsild Gletscher is likely to undergo tidal motion as well. The pattern of tidal motion probably reflects the interplay of the grounding zones from both glaciers.

To explain the pattern of tidal motion derived from the interferometric data and to characterize the flexural rigidity of the ice, I compared a tidal profile extracted along the western half of the ice tongue (Fig. 1) with model predictions from an elastic beam of infinite length, with one end rigidly clamped on bedrock (Holdsworth, 1977). The predicted tidal amplitude at time $t$ and abscissa $x$ along the beam is

$$
Z_{t, x}=Z_{t}\left\{1-\mathrm{e}^{-\beta x}[\cos (\beta x)+\sin (\beta x)]\right\}
$$

where $Z_{t}$ is the asymptotic value of the tidal displacement at time $t$ referenced to mean sea level, and $\beta$ is the elastic damping factor of the ice given by

$$
\beta^{4}=3 \rho_{\mathrm{w}} g\left(1-\nu^{2}\right) E^{-1} h^{-3}
$$

where $E$ is Young's elastic modulus of ice, $\rho_{\mathrm{w}}=$ $1030 \mathrm{~kg} \mathrm{~m}^{-3}$ is the density of sea water, $g=9.81 \mathrm{~m} \mathrm{~s}^{-2}$ is the acceleration of gravity, $\nu=0.3$ is the Poisson coefficient for ice, and $h$ is the glacier thickness. The best fit is obtained for $\beta=(4.7 \pm 0.1) \times 10^{-4} \mathrm{~m}^{-1}$, with a rms fit error of $0.8 \mathrm{~mm}$ (Fig. 6).

Judging from the low rms error and the high number of points used in the comparison, the model predictions fit the measurements very well and explain the pattern of tidal displacements measured by radar interferometry. The inferred value of $\beta$ is in reasonable agreement with the curve of Vaughan (1995) relating $\beta$ to the ice thickness at the grounding line. To obtain a measurement point lying exactly on his curve, the glacier thickness would have to be $863 \mathrm{~m}$, or $288 \mathrm{~m}$ thicker than the ice 


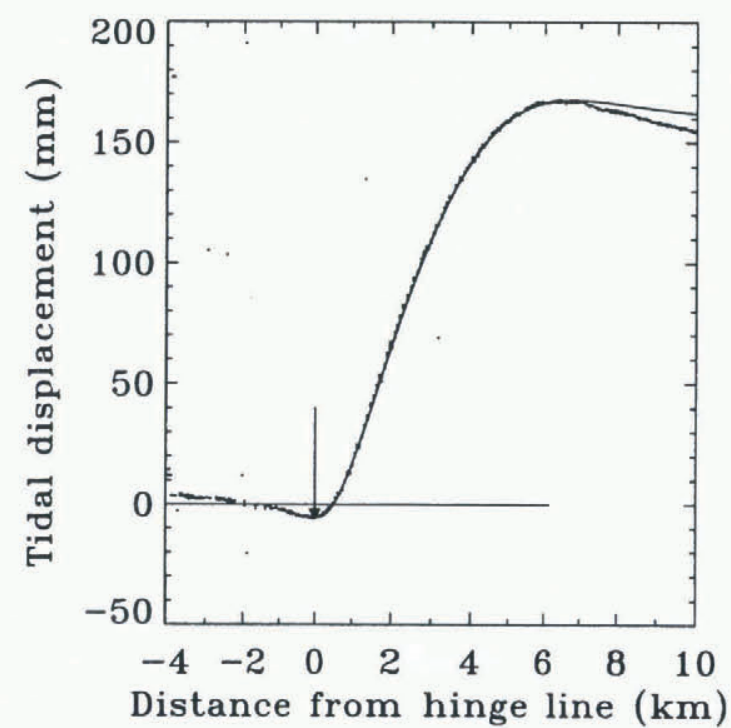

Fig. 6. Tidal displacements (dots) along a $160 \mathrm{~m}$ wide profile shown in Figure 1, compared to model predictions (solid line) from an elastic-beam theory. The arrow points to the area of maximum bending stress, or hinge line.

thickness measured by an ice-sounding radar (see below). In an equivalent fashion, the value of $E$ calculated from Equation (7) is $3 \pm 0.2 \mathrm{GPa}$, or three times larger than the value derived by Vaughan (1995) using data from several glaciers. Hence, the method of using Equation (7) is probably not a sensitive predictor of the elastic modulus of the ice.

Residual errors in model fitting are present downstream from the point of maximum tidal deflection (Fig. 6), where we earlier noticed the presence of residual phase errors running across the scene. These errors remain small compared to the tidal displacements recorded on the ice tongue.

\section{Hinge line and grounding line}

In the elastic-beam theory (Holdsworth, 1969), the bending stress of the ice, $\sigma_{x x}=E z \dot{\epsilon}_{x x}\left(1-\nu^{2}\right)^{-1}$, where $z$ is the vertical distance to the neutral axis of the beam, and $\dot{\epsilon}_{x x}$ is the bending strain rate, is maximum at the ice surface for $z= \pm h / 2$ and at the hinge line for $x=0$. Locating the maximum of the bending stress, however, involves second-order derivatives of the phases, which increase the noise level of the data. Instead, I propose to define the interferometric grounding line as the location of the minimum relative tidal displacement measured along a tidal profile extracted in the glacier-flow direction (Fig. 6). In the elastic-beam theory, the point of minimum deflection also coincides with the hinge line.

The hinge line may not necessarily coincide with the grounding line or with the line of hydrostatic equilibrium of the glacier (Smith, 1991). The grounding line is typically downstream from the hinge line and upstream from the line of hydrostatic equilibrium. On Petermann Gletscher these three zones are separated by $1-2 \mathrm{~km}$, as discussed later.

The hinge line of Petermann Gletscher is shown in Figure 3, overlaid on the tidal displacements. Based on the phase noise of the tidal signal (Fig. 6), I estimate that the hinge line can be detected within 1 pixel or $20 \mathrm{~m}$. Near the center of the glacier, the precision is less, because the hinge line shifts in the cross-track direction by several pixels over an across-flow distance of about $500 \mathrm{~m}$, and the tidal profile no longer exhibits a sharp minimum. At the glacier margin, the hinge line cannot be detected accurately, since the fringe rate is too high, phase coherence is much lower and the phase values cannot be unwrapped.

The achieved mapping precision still remains more than one order of magnitude superior to that quoted by Goldstein and others (1993) who utilized a single radar interferogram. The reason for the lower precision of the single interferogram technique is that it includes the longitudinal gradients in ice velocity which tend to smooth out the local minimum in tidal displacement and bias its location. Here, the bias in absolute location is of the order of several hundred meters. In order to map the hinge line of a floating glacier precisely, it is therefore essential to utilize multiple interferograms and eliminate the longitudinal gradients in ice velocity.

\section{Ice velocities}

The ice velocity varies from $400 \mathrm{~m} \mathrm{a}^{-1}$ at $900 \mathrm{~m}$ elevation to $1100 \mathrm{ma}^{-1}$ at the grounding line, decreasing thereafter to about $900 \mathrm{~m} \mathrm{a}^{-1}$ toward the edge of the scene (Fig. 7). Removal of the tidal signal clearly reduces the variations in ice velocity across the grounding line, yielding a more reasonable velocity profile.

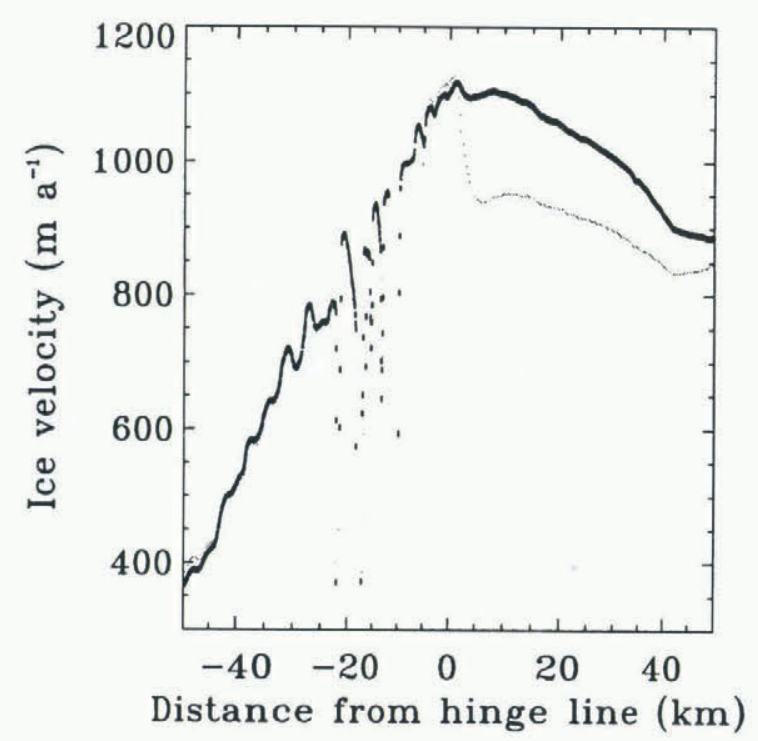

Fig. 7. Ice velocities in the flow direction along the glacier center line before (dotted, grey line) and after (solid line) tidal corrections. The width of the profile is $80 \mathrm{~m}$.

In several parts of the floating section of the glacier, large discontinuities in ice velocity are detected (Fig. 4). Along the center line, the eastern slab of the floating ice tongue moves about $30-50 \mathrm{~m} \mathrm{a}^{-1}$ faster than the western slab. About $20 \mathrm{~km}$ downstream from the grounding line, where the velocity difference between the two slabs reaches $50 \mathrm{~m} \mathrm{a}^{-1}$, the velocity of the eastern slab abruptly decreases by $40 \mathrm{~m} \mathrm{a}^{-1}$. The discontinuity in velocity and apparent surface rupture reveals an overriding of the 
northern slab by the faster-moving southern slab. A further $20 \mathrm{~km}$ downstream, a similar discontinuity in velocity occurs on the western side of the glacier. The two slabs subsequently move at comparable speeds.

These discontinuities in ice velocity occur in the turning section of the glacier. Surface rupturing could be due to the differential velocity between the two sides of the glacier associated with flow turning. Overriding of the ice indicates that the resistance to ice flow is larger downstream from the grounding line, during the glacier turn, which is consistent with additional friction at the side margins during flow turning.

\section{Ice thickness}

I estimated the glacier thickness using the KMS DEM data by assuming that the floating glacier ice tongue is in hydrostatic equilibrium. To perform this calculation, I used an ice density of $917 \mathrm{~kg} \mathrm{~m}^{-3}$ and a density of sea water of $1030 \mathrm{~kg} \mathrm{~m}^{-3}$. The corresponding values of the ice thickness averaged across the glacier width, $\bar{h}$, are shown in Figure 8, with error bars corresponding to one standard deviation in ice thickness across the glacier width.

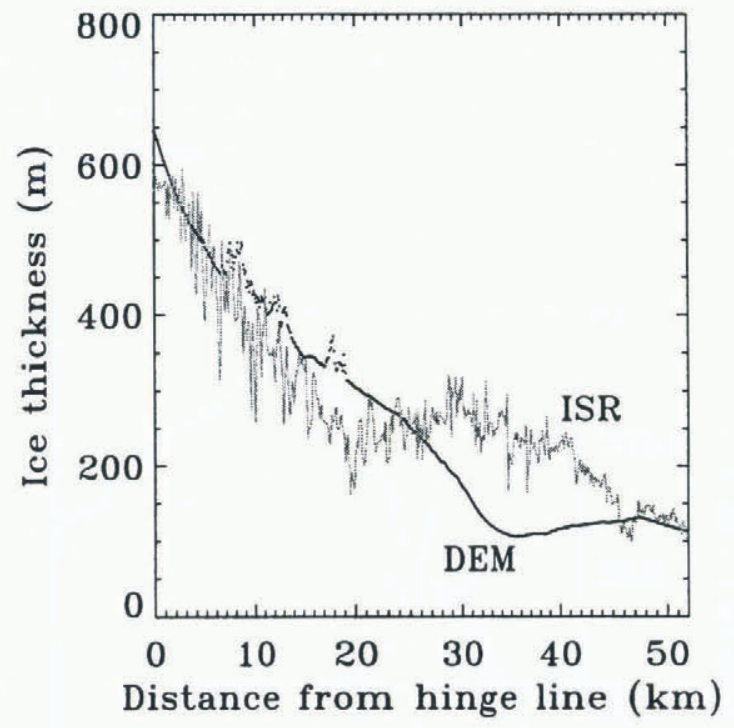

Fig. 8. Ice thickness measured by the University of Kansas's airborne ice-sounding radar (ISR, grey line) along the glacier center line compared with the ice thickness deduced from the KMS data (DEM, solid line) assuming hydrostatic equilibrium of the ice and averaged across the glacier width.

Ice thickness was coincidentally measured by an airborne ice-sounding radar, designed and operated by the University of Kansas (Chuah and others, 1996) and flying on board a NASA P-3 aircraft, along the center line of Petermann Gletscher, on 26 May 1995. The icesounding radar operates a coherent radar system at a center frequency of $150 \mathrm{MHz}$.

At the hinge line, ice thickness is slightly overestimated by the DEM data (Fig. 8). The two thickness estimates become equal at about $2.7 \pm 0.5 \mathrm{~km}$ from the hinge line, which indicates the approximate location of the line of hydrostatic equilibrium of the glacier tongue. Between $\mathrm{km} 25$ and 45, the ice-sounding radar indicates a larger ice thickness than calculated from hydrostatic equilibrium of the ice. Conversely, between $\mathrm{km} 5$ and 25, ice thickness is slightly overestimated by the DEM data. If the KMS DEM is accurate, this result suggests that either a large part of the ice tongue is not in hydrostatic equilibrium, or the ice-sounding radar data include spatial irregularities in ice thickness that do not correspond to steady-state conditions. Multiple icesounding radar profiles are needed to interpret these differences more completely.

About $1 \pm 0.5 \mathrm{~km}$ from the hinge line, the icesounding radar data transition to a regime of larger variations in ice thickness (Fig. 8) and the basal reflections produce hyperbolic radio-echo records (Jezek and others, 1995). This feature is likely caused by bottom crevassing of the glacier and indicates the approximate position of the grounding line (Jezek and others, 1995). The grounding line, the hinge line and the line of hydrostatic equilibrium of Petermann Gletscher are therefore not coincident and are probably separated by about $1-2 \mathrm{~km}$.

\section{Ice discharge}

The ice flux, $Q$, from Petermann Gletscher at and below the hinge line is calculated using

$$
Q=\bar{h} \bar{V}_{x} W_{y}
$$

where $\bar{V}_{x}$ is the ice velocity along the $x$ direction averaged across the glacier width, and $W_{y}$ is the glacier width measured in the $y$ direction (Paterson, 1994). The glacier thickness used in the calculation is that derived from the KMS data. Where the glacier is afloat, basal velocities should equal the surface velocities, so the surface velocities measured by radar interferometry are equivalent to vertically integrated ice velocities.

Ice discharge is $12.3 \pm 1 \mathrm{~km}^{3} \mathrm{a}^{-1}$ at the hinge line and $12.1 \pm 1 \mathrm{~km}^{3} \mathrm{a}^{-1}$ about $1 \mathrm{~km}$ downstream where the glacier is more likely to be in hydrostatic equilibrium

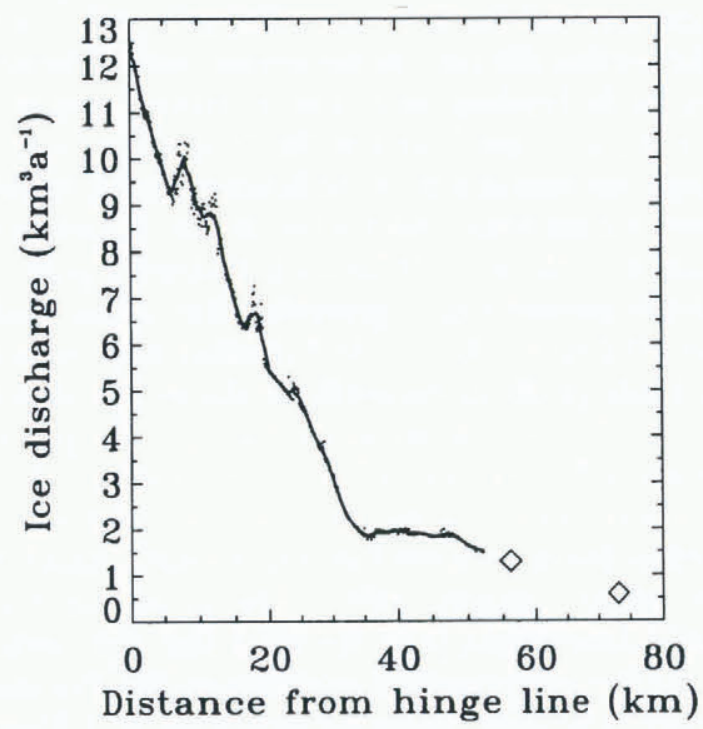

Fig. 9. Ice discharge (dots) of Petermann Glelscher at and below the hinge line, and average discharge (solid line) averaged over $1.5 \mathrm{~km}$ segments. Diamond symbols indicate the ice-flux estimates by Higgins (1991). 
(Fig. 9). The measurement error is associated with uncertainties in ice velocity at the ice margin, and with uncertainties in ice thickness. About $30 \mathrm{~km}$ upstream from the hinge line, Joughin and others (1995b) estimated an ice flux of $12.7 \mathrm{~km}^{3} \mathrm{a}^{-1}$, consistent with our results. Downstream from the hinge line, the ice discharge decreases rapidly. At $\mathrm{km} \mathrm{52,} \mathrm{the} \mathrm{ice} \mathrm{discharge} \mathrm{is} \mathrm{only}$ $2.1 \mathrm{~km}^{3} \mathrm{a}^{-1}$. These results are consistent with those obtained by Higgins (1991) near the ice front (Fig. 9). At the glacier front, Higgins (1991) estimated a calf-ice production of only $0.59 \mathrm{~km}^{3} \mathrm{a}^{-1}$, or 20 times smaller than the ice discharge at the hinge line. Ablation processes therefore melt more than $95 \%$ of the ice that crosses the hinge line. Calf-ice production plays a minor role in the mass discharge to the ocean from Petermann Gletscher.

\section{Melt rates}

Assuming that the ice density is everywhere the same, the equation of mass conservation integrated vertically and across the glacier width is

$$
\frac{\partial Q}{\partial x}+\frac{\partial \bar{h}}{\partial t}=W_{y} \dot{b}
$$

where $\dot{b}$ is the glacier net balance, positive if the glacier accumulates mass (Paterson, 1994). I now assume that the glacier is in steady-state conditions, meaning $\partial \bar{h} / \partial t=$ 0 , and calculate the glacier net balance, $\dot{b}$, from the gradient in ice flux divided by the glacier width.

The largest source of error is the uncertainty in thickness gradient. To reduce that error, I calculate the glacier net balance at a discrete number of locations, over $5-10 \mathrm{~km}$ long segments. The results are shown in Figure 10. The largest value, about $24 \pm 5 \mathrm{ma}^{-1}$, is recorded close to the grounding line. Near the ice front, the glacier net balance is only $2-3 \mathrm{~m} \mathrm{a}^{-1}$ (Higgins, 1991). The ice flux decreases from 12.1 to $1.5 \mathrm{~km}^{3} \mathrm{a}^{-1}$ over an ablation area of $886 \mathrm{~km}^{2}$, corresponding to an average melt rate of $12 \pm 2 \mathrm{ma}^{1}$.

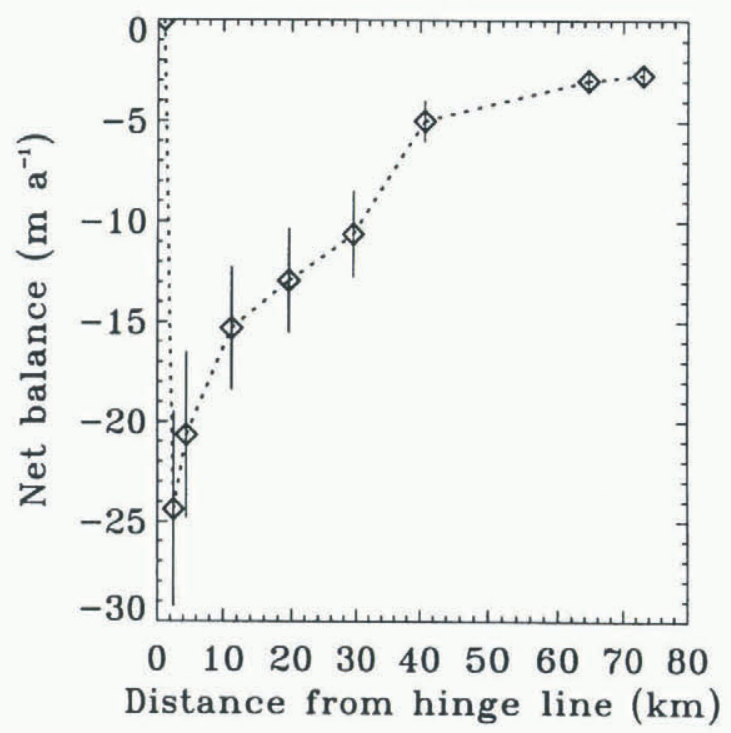

Fig. 10. Melt rate of the floating ice tongue os the downstream distance from the hinge line with $20 \%$ error bars.

\section{DISCUSSION}

The hinge line of Petermann Gletscher may move back and forth with the ocean tide, depending on the geometry of the hinge zone (Holdsworth, 1977). The KMS DEM indicates that the glacier slope at the center of the glacier is about $0.8 \%$ at the hinge line, $1 \% 4 \mathrm{~km}$ above, and $0.2 \% 4 \mathrm{~km}$ below. The tide amplitudes of Thank God Harbor $\left(81^{\circ} 36^{\prime} \mathrm{N}, 61^{\circ} 40^{\prime} \mathrm{W}\right)$ were measured by C. F. Hall during the Polaris expedition around 1871 (personal communication from R. Forsberg, 1996) and indicate that the maximum tidal displacement recorded over a $3 \mathrm{~d}$ repeat-pass cycle should not exceed $800 \mathrm{~mm}$. Assuming that the bedrock slope is $0.8 \%$, short-term variations in sea level should not displace the hinge line by more than $100 \mathrm{~m}$ or 5 pixels. Larger displacements of the hinge line would indicate a change in glacier thickness of $1 \mathrm{~m}$ per $125 \mathrm{~m}$ of horizontal displacement, assuming that other effects, such as the isostatic uprise of the seabed, are negligible during that time period. Using the interferometric hinge line as a reference, it should be possible to detect fine changes in glacier conditions.

The pattern of ice discharge from Petermann Gletscher is unexpected. Close to the ice front, Higgins (1991) measured a rate of glacier thinning of $2.7 \mathrm{~m} \mathrm{a}^{-1}$ in the last $17 \mathrm{~km}$ of glacial flow, which he attributed to surface ablation. If we assume a surface ablation rate of about $2-3 \mathrm{~m} \mathrm{a}^{-1}$ for the ice tongue, glacier thinning near the grounding line cannot be attributed to surface ablation alone. A significant amount of ice must be removed through basal melting. The signature of the radar echoes from the ice-sounding radar (not shown here) supports that conclusion (Jezek and others, 1995). The basal melt rate of Petermann Gletscher should average about $10 \pm 2 \mathrm{ma}^{-1}$, with peak values exceeding $20 \mathrm{ma}^{-1}$ near the grounding line.

The melt rates of floating ice tongues or ice shelves are poorly known near the grounding line, and it is not well known how soon high rates of melting develop (Jacobs and others, 1992). Here, basal melting is most active in the first $45 \mathrm{~km}$ downstream from the hinge line. The pattern of melt rate shown in Figure 10 is consistent with earlier observations conducted by Jenkins and Doake (1991, fig. 10) for the Filchner-Ronne Ice Shelf or Thomas (1976, fig. 5) for the Ross Ice Shelf.

The same mechanisms which control basal melting on an ice shelf must be acting on the ice tongue of Petermann Gletscher. These mechanisms are well known and correspond to a large-scale ice pump (Lewis and Perkin, 1986). In an ice pump, deep thermohaline convection is induced by melting of ice in the deepest part of the floating ice and driven by the pressure dependence of the freezing point. Marine ice accumulates at the base of the glacier, as ice platelets rising in the water column accrete to the bottom of the ice shelf (Oerter and others, 1992). In the case of Petermann Gletscher, the ice-pump effect must be amplified by strong tidal pumping and mixing of the water column. Oceanographic observations are needed to determine the characteristics of the water column and confirm the existence of strong basal melting.

One other possible interpretation of the net balance data is that the glacier is not in steady-state conditions and is actually thickening. The corresponding thickening 
rate is large and would suggest a major change in mass balance of Petermann Gletscher. Joughin and others (1995a), however, found that the ice discharge from the equilibrium line of Petermann Gletscher was nearly in balance with its accumulation. Their result argues strongly in favor of assuming steady-state conditions for the ice tongue.

In Greenland, it is generally assumed that ice removal proceeds through surface ablation and calf-ice production (Reeh, 1985). This is not true of Petermann Gletscher, where calf-ice production and surface ablation are small compared to basal melting. Ice tongues like that of Petermann Gletscher do not develop extensively in the Arctic, but are present in other parts of northern Greenland. For mass-balance studies, and in order to avoid the difficulty of measuring the basal melt rates of the ice tongues, it seems essential to estimate ice discharge at the grounding line, instead of combining estimates of surface ablation and calf-ice production.

In Antarctica, where far more glaciers develop a floating ice tongue or an ice shelf, basal melting is already known to play an important role in the overall mass balance of the ice sheet (Jacobs and others, 1992). Recent studies of Pine Island Glacier (Jacobs and others, 1996) and Rutford Ice Stream (Jenkins and Doake, 1991; Smith, in press) also show that basal melt rates of the magnitude of those detected on Petermann Gletscher are not unlikely. These results taken together make it more imperative to measure ice discharge of polar ice sheets at the grounding line rather than at the ice front.

Radar interferometry appears to be a powerful technique for locating the grounding line with precision and providing essential information to calculate ice discharge. Ice thickness could be estimated from interferometrically derived topographic data in places where the ice is in hydrostatic equilibrium, but more direct means of measuring ice thickness are probably desirable to increase confidence in the results.

\section{CONCLUSIONS}

Multiple repeat-pass ERS-1 radar observations of Petermann Gletscher were utilized to map the tidal displacements of its floating ice tongue and the hinge line of the glacier at an unprecedented level of spatial detail. This technique is a great tool for monitoring the transition between grounded ice sheet and ice rises from floating ice shelves which is known to be very sensitive to small changes in ocean conditions, ice discharge activity or isostatic uprise of the seabed.

Melt rates of the ice tongue of Petermann Gletscher deduced from the interferometric velocities and icethickness data appear to be very high, especially near the grounding line. These high melt rates are attributed to pronounced basal melting of the ice tongue at about $10 \pm 2 \mathrm{ma}^{-1}$. Further studies are needed to confirm these estimates and determine the oceanographic conditions that induce such a high rate of basal melting. The results already suggest, however, that, even in the Arctic, basal melting can be a significant component of the mass release from the major outlet glaciers draining an ice sheet.

\section{ACKNOWLEDGEMENTS}

This work was performed at the Jet Propulsion Laboratory, California Institute of Technology, under a contract with the National Aeronautics and Space Administration. I would like to thank S. Ekholm and R. Forsberg for graciously providing a high-quality topographic map of Petermann Gletscher, C. Werner for use of his SAR processor, K. Jezek for enriching discussions on the glaciology and dynamics of Petermann Gletscher and for pointing out the importance of basal melting, and P. Gogineni for sharing in advance of publication his ice-sounding radar observations.

\section{REFERENCES}

Chuah, T.S., S. P. Gogineni, C. Allen and B. Wohletz. 1996. Radar thickness measurements over the northern part of the Greenland ice sheet. Lawrence, KS, University of Kansas. Radar Systems and Remote Sensing Laboratory. (Technical Report 10470-3.)

Drewry, D.J. and G. de Q. Robin. 1983. Form and flow of the Antarctic ice sheet during the last million years. In Robin, G. de Q., ed. The climatic record in polar ice sheets. Cambridge, etc., Cambridge University Press, 28-38.

Dunbar, M. 1978. Correspondence. Petermann Gletscher: possible source of a tabular iceberg off the coast of Newfoundland. $f$. Glaciol., 20 (84), 595-597.

Gabriel, A. K., R. M. Goldstein and H. A. Zebker. 1989. Mapping small elevation changes over large areas: differential radar interferometry. J. Geophys. Res., 94(B7), 9183-9191.

Goldstein, R. M. 1995. Atmospheric limitations to repeat-track radar interferometry. Geophys. Res. Lell., 22(18), 2517-2520.

Goldstein, R. M., H. A. Zebker and C. L. Werner. 1988. Satellite radar interferometry: two-dimensional phase unwrapping. Radio Sci., 23 (4), 713-720.

Goldstein, R. M., H. Engelhardt, B. Kamb and R. M. Frolich. 1993. Satellite radar interferometry for monitoring ice sheet motion: application to an Antarctic ice stream. Science, 262 (5139), 1525-1530.

Hartl, P., K. -H. Thiel, X. Wu, C. S. M. Doake and J. Sievers. 1994. Application of SAR interferometry with ERS-1 in the Antarctic. Earth Observation Quarterly, 43, 1-4.

Higgins, A. K. 1991. North Greenland glacier velocities and calf ice production. Polarforschung, 60 (1), 1990, 1-23.

Holdsworth, G. 1969. Flexure of a floating ice tongue. f. Glaciol., 8 54), 385-397.

Holdsworth, G. 1977. Tidal interaction with ice shelves. Ann. Géophys., $33(1-2), 133-146$.

Jacobs, S.S., H. H. Helmer, C. S. M. Doake, A. Jenkins and R. M. Frolich. 1992. Melting of ice shelves and the mass balance of Antarctica. J. Glaciol., 38(130), 375-387.

Jacobs, S. S., H. H. Helmer and A. Jenkins. 1996. Antarctic ice sheet melting in the southeast Pacific. Geophys. Res. Lett., 23(9), 957-960.

Jenkins, A. and C. S. M. Doake. 1991. Ice-ocean interaction on Ronne Ice Shelf, Antarctica. J. Geophys. Res., 96 (C1), 791-813.

Jezek, K. C., P. Gogineni and E. Rignot. 1995. Radio echo sounding of outlet glaciers, western Greenland. [Abstract.] EOS, 76(46), Fall Meeting Supplement, F183.

Joughin, I., R. Kwok, M. Fahnestock, S. Gogineni and C. Allen. 1995a. Interferometrically derived topography, velocity, and ice-flux estimates for the Petermann Glacier. [Abstract.] EOS, 76 (46), Fall Meeting Supplement, F184.

Joughin, I. R., D. P. Winebrenner and M.A. Fahnestock. 1995b. Observations of ice-sheet motion in Greenland using satellite radar interferometry. Geophys. Res. Lett., 22(5), 571-574.

Kollmeyer, R. C. 1980. West Greenland outlet glaciers: an inventory of the major iceberg producers. International Association of Hydrological Sciences Publication 126 (Riederalp Workshop 1978 - World Glacier Inventory), 57-65.

Lewis, E. L. and R.G. Perkin. 1986. Ice pumps and their rates. $f$. Geophys. Res., 91 (C10), 11,756-11,762.

Oerter, H. and 6 others. 1992. Evidence for basal marine ice in the Filchner-Ronne Ice Shelf. Nature, 358 6385), 399401.

Paterson, W.S. B. 1994. The physics of glaciers. Third edition. Oxford, etc., Elsevier. 
Reeh, N. 1985. Greenland ice-sheet mass balance and sea-level change. In Glaciers, ice sheets, and sea level: effect of a $\mathrm{CO}_{2}$-induced climatic change. Report of a Workshop held in Seattle, Washington, September 13-15, 1984. Washington, DC, U.S. Department of Energy. Office of Energy Research, 155-171. (Attachment 8, Report DOE/ER/60235-1.)

Rignot, E. 1995. Backscatter model for the unusual radar properties of the Greenland ice sheet. F. Geophys. Res., 100 (E5), 9389-9400.

Rignot, E.J., S.J. Ostro, J.J.van Zyl and K. C. Jezek. 1993. Unusual radar echoes from the Greenland ice sheet. Science, $261(5129), 1710-$ 1713.

Rignot, E., K. C. Jezek and H. G. Sohn. 1995. Ice flow dynamics of the Greenland ice sheet from SAR interferometry. Geophys. Res. Lett., $22(5), 575-578$.

Smith, A. M. 1991. The use of tiltmeters to study the dynamics of Antarctic ice-shelf grounding lines. J. Glaciol., 37 (125), 51-58.

Smith, A. M. In press. Ice shelf basal melting at the grounding line, measured from seismic observations. JGR Oceans.
Thomas, R. H. 1976. Thickening of the Ross Ice Shelf and equilibrium state of the West Antarctic ice sheet. Nature, 259 5540), 180-183.

Thomas, R. H. and C. R. Bentley. 1978. A model for Holocene retreat of the West Antarctic ice sheet. Quat. Res., 10 2), 150 170.

Vaughan, D. G. 1995. Tidal flexure at ice shelf margins. 7. Geophys, Res., 100 B 4$), 6213-6224$.

Vaughan, D. G. and C.S.M. Doake. 1996. Recent atmospheric warming and retreat of ice shelves on the Antarctic Peninsula. Nalure, 379 (6563), 328-331.

Zebker, H.A. and R. M. Goldstein. 1986. Topographic mapping from interferometric synthetic aperture radar observations. J. Geophys. Res., 91 (B5), 4993-4999.

Zebker, H.A., P.A. Rosen, R. M. Goldstein, A. Gabriel and C. L. Werner. 1994. On the derivation of coseismic displacement fields using differential radar interferometry: the Landers earthquake. J. Geophys, Res., 99 (B10), 19,617-19,634.

MS received 21 March 1996 and accepted in revised form 15 June 1996 